\title{
Moisture Absorption in Uncured Underfill Materials
}

\author{
Shijian Luo, Member, IEEE, and C. P. Wong, Fellow, IEEE
}

\begin{abstract}
This paper presents a systematic study on moisture absorption in uncured underfill based on epoxy cured with acid anhydride [methylhexahydrophthalic anhydride (MHHPA)] and epoxy cured with non-acid anhydride curing agent. The influence of absorbed moisture on curing properties, thermomechanical property, and adhesion property of underfill after curing has been investigated. For epoxy cured with non-acid anhydride, the moisture absorption is low, and the absorbed moisture has no significant effect on the properties of cured underfill materials. For epoxy cured with acid anhydride, the moisture absorption before curing can be more than $2.0 \%$, and the absorbed moisture can affect the properties significantly. The absorbed moisture can catalyze the curing reaction between acid anhydride and epoxy. The glass transition temperature of the cured samples is reduced after the underfill absorbs the moisture before curing. The adhesion strength decreases dramatically after the underfill absorbs the moisture before curing.
\end{abstract}

Index Terms-Adhesion, epoxy, moisture absorption, underfill.

\section{INTRODUCTION}

$\mathbf{F}$ LIP CHIP is a packaging approach in which the integrated circuit (IC) is connected to the substrate through solder joints with the active side facing down. Flip chip technology is a packaging approach to meet high input/output (I/O) count due to its area array of interconnection onto substrate. In addition, it has fast signal propagation because of its short interconnection path. It is a key method to improve packaging density, reliability, and cost in electronic products. In the earlier days of flip chip technology, the IC chips were attached to ceramic substrates where there was no significant problem in coefficient of thermal expansion (CTE) mismatch, thus no significant thermal stress was generated on the solder joints. When organic substrate such as FR-4 and polyimide (PI) is used, however, significant thermal stress is generated on the solder joints during thermal cycling of the assembly, due to the great difference in CTE between the silicon die and the organic substrate. This stress is proportional to the distance from the neutral point of the die, and it can lead to failure of the solder joint interconnection. Underfill, which is used to enhance the solder joint fatigue reliability of a flip chip device, is one of the key materials in flip chip technology. The introduction of underfill material between the die and substrate

Manuscript received May 15, 2002; revised December 2, 2003. This work was supported by the National Institute of Standards and Technology through the Advanced Technology Program (ATP). This paper was presented at the 52nd Electronic Components and Technology Conference, San Diego, CA, 2002. This work was recommended for publication by Associate Editor D. N. Donahoe upon evaluation of the reviewers' comments.

S. Luo currently works for Assembly Department, Micron Technology, Inc., Boise, ID 83707-0006 USA (e-mail: sluo@ micron.com).

C. P. Wong is with the Packaging Research Center, School of Materials Science and Engineering, Georgia Institute of Technology, Atlanta, GA 30332 USA (e-mail: cp.wong@mse.gatech.edu).

Digital Object Identifier 10.1109/TCAPT.2004.828562 can greatly improve the solder joint fatigue life by mechanically coupling the substrate and die, and making the system stiffer [1], [2]. The underfill provides not only thermo-mechanical protection but also environmental protection to the flip-chip assembly. There are several requirements for the underfill material, which include high modulus, high glass transition temperature, solder-matching CTE, low moisture absorption, and good adhesion. In current flip chip with underfill process, underfilling process is done on individual chip during assembling. The main steps involve aligning the bumped chip with the substrate bond pads, reflow of the solder to get a good metallurgical joint, cleaning the flux, underfill dispensing, and curing. Underfilling is performed on a discrete integrated circuit (IC) chip. As such, it is slow, and it is not a standard process. Thus it is a bottleneck in the process line. No-flow underfill and its process have been developed to eliminate the long underfill filling time and combine the curing of underfill and solder reflow in one step [3]. Molded underfill is developed for flip chip in packaging application [4]. However, underfilling process is still performed on individual discrete IC. Underfill that is pre-applied to wafer and can be reworked will be needed for high volume direct chip attachment (DCA) to become mainstream in 2005. For this reason, many research resources are devoted to develop a novel underfill material and a wafer level process for deposition. Instead of dispensing the conventional underfill into the gap between the chip and substrate after solder joint formation, wafer level underfill (preapplied underfill) material is applied directly onto the wafer, and B-staged. The wafer is then diced into individual discrete chips, and further assembled onto the substrate; final curing of underfill and solder joint connection occur simultaneously during solder reflow. Conventional capillary flow underfill, no-flow underfill, molded underfill, and wafer level underfill have different issues and concerns, and are compared in literature [4], [5].

Underfill is mainly silica filled epoxy. Epoxy has excellent properties such as good adhesion to many substrates due to the presence of highly polar hydroxyl and ether groups. However, unlike metals and ceramics, epoxy cannot provide a hermetic encapsulation. The permeability of moisture in organic material such as epoxy is orders of magnitude higher than in metals or ceramics. Absorbed moisture affects the thermo-mechanical properties of epoxy materials, reducing the glass transition temperature $\left(\mathrm{T}_{\mathrm{g}}\right)$, the modulus, and the strength, especially at high temperatures. Moisture diffusion through epoxy is the major cause of corrosion of metals in electronic packaging. The adhesion of an epoxy to a substrate may be affected when moisture is absorbed by the epoxy. Moisture may also be absorbed by uncured epoxy, thus affecting the curing properties of epoxy and the thermomechanical properties of the cured material [6]. For wafer level underfill material, there will be a significant 
amount of time between the application of underfill onto wafer and final curing of underfill during assembling. There is moisture in the environment and the underfill can absorb the moisture from the environment. There has not been systematic study on the moisture absorption of wafer level underfill before curing and its influence on the final properties. This paper discusses the moisture absorption of wafer level underfill materials before the final curing and its influence on the final curing, adhesion, and thermo-mechanical properties of underfill materials after curing. It was discovered that epoxy cured with non-acid anhydride as curing agent has low moisture absorption, and the absorbed moisture has no significant effect on the adhesion and thermo-mechanical property of cured underfill. However, epoxy cured with acid anhydride showed significant amount of moisture absorption in uncured underfill, and the absorbed moisture adversely affects the adhesion and thermomechanical property of cured underfill materials.

\section{EXPERIMENTAL}

\section{A. Materials and Underfill Formulation}

All of the materials in this study were used as received from the following manufacturers and vendors. The cycloaliphatic epoxy resin (ERL4221, EEW value: 134 g/equivalent) was from Union Carbide. The bisphenol-A epoxy (EPON8281, EEW value: $187 \mathrm{~g}$ /equivalent) was from Shell Chemicals. The hardener, 4-methylhexahydrophthalic anhydride (MHHPA), was from Aldrich Chemicals. Hardener phenolic resin LBR-2 with a hydroxyl equivalent weight (HEW) of 102 g/equivalent was from Sumitomo Plastics America, Inc. Amine type curing agent methylenedianiline (MDA) with molecular weight of $198 \mathrm{~g} / \mathrm{mol}$ was from Aldrich Chemicals. The catalysts, cobalt (II) acetylacetonate (CAA), and dimethylbenzylamine (DMBA) were also from Aldrich Chemicals. The imidazole derivative 2E4MZ-CN (1-cyanoethyl-2-ethyl-4-methylimidazole) was from Shikoku Chemicals.

First, 0.8 equivalent of MHHPA was mixed with 1 equivalent of epoxy. Then the desired amount of the catalyst was added into the mixture. The catalyst loading was as follows: CAA ( $0.4 \%$ of total weight of resin and hardener), tertiary amines ( $1 \%$ of total weight of resin and hardener), imidazole derivatives $(0.4 \%$ of total weight of resin and hardener). When coupling agent (CA) was used, the concentration of coupling agent CA-1 (epoxy silane) or CA-2 (amino silane) is $6 \mathrm{mmol}$ per $100 \mathrm{~g}$ of underfill.

Model underfill formulations were also prepared with non-acid anhydride curing agent. When phenolic resin was used as curing agent, 1.0 equivalent of epoxy resin was mixed with 1.0 equivalent of LBR-2, and then the catalyst of $1 \%$ of the total weight of the mixture was added into the mixture of epoxy resin and hardener. When amine was used as curing agent, one equivalent of EPON8281 was mixed with 0.25 mole of MDA. When imidazole derivative was used as hardener, 100 parts of EPON8281 was mixed with six parts of 2E4MZ-CN.

\section{B. Die Shear Sample Preparation and Die Shear Test}

Silicon dies $(2 \times 2 \mathrm{~mm}$ and $20 \times 20 \mathrm{~mm})$ with different passivation $[\mathrm{SiN}$, benzocyclobutene $(\mathrm{BCB})$, or polyimide $(\mathrm{PI})]$ were cleaned according to the standard procedure mentioned in the [7]. The steps were as follows: 5 min soak in terpene; $5 \mathrm{~min}$ soak in terpene during ultrasonic cleaning; 5 min soak in isopropyl alcohol; 5 min soak in isopropyl alcohol during ultrasonic cleaning; 3 rinses in deionized water; and dry in oven at $120{ }^{\circ} \mathrm{C}$ for 30 min under vacuum. Glass beads $(0.5 \%$ weight of underfill), with a diameter of $75 \mu \mathrm{m}$, were used as spacers to control the gap between the top and bottom dies. The small die $(2 \times 2 \mathrm{~mm})$ was dipped into a thin liquid film of the underfill to coat a uniform thin layer, and then placed on the large die $(20 \times 20 \mathrm{~mm})$. The assembled die shear samples were placed in different environment for certain time, and were then cured according to their individual prescribed curing schedules. Die shear testing was performed $12 \mathrm{~h}$ after the samples were cured. The die shear test was performed on a die bond tester (Model $550-100 \mathrm{~K}$, Royce Instruments) with a blade speed of $0.2 \mathrm{~mm} / \mathrm{s}$. The die shear strength is reported in MPa.

\section{Moisture Absorption}

The uncured underfill materials were poured into pans. The thickness of the underfill materials was about $2 \mathrm{~mm}$. The materials were placed in ambient lab environment around $22{ }^{\circ} \mathrm{C} 40-50 \%$ relative humidity. The weight of the samples was recorded at different time. The percentage of weight gain was defined as the moisture absorption.

\section{Differential Scanning Calorimeter (DSC) Experiment}

About $10 \mathrm{mg}$ of the underfill material was placed in a nonhermetic DSC pan. The pan was placed in normal lab environment at $22{ }^{\circ} \mathrm{C} 40-50 \%$ relative humidity for certain time to allow the material to absorb moisture. Then, the curing profile was recorded up to $300{ }^{\circ} \mathrm{C}$ with a differential scanning calorimeter (DSC, Model 2920, TA Instruments) with a heating rate of $5{ }^{\circ} \mathrm{C} / \mathrm{min}$ under $\mathrm{N}_{2}$ purge gas. After cooling to room temperature, a subsequent heating scan was performed to determine the glass transition temperature after curing at a heating rate of $5^{\circ} \mathrm{C} / \mathrm{min}$.

\section{E. Characterization of Thermo-Mechanical Properties}

The underfill was cured in an aluminum pan. The cured underfill sample was polished until a uniform thickness of about $2 \mathrm{~mm}$ was achieved. A small piece of specimen with dimensions of $5 \times 5 \mathrm{~mm}$ was cut from the sample. A thermomechanical analyzer [(TMA), TA Instruments, Model 2940] was used to measure the thermal expansion of the specimen under $\mathrm{N}_{2}$ purge gas with a heating rate of $5^{\circ} \mathrm{C} / \mathrm{min}$.

A strip with a width of $4 \mathrm{~mm}$ was cut from the disk. The dynamic mechanical analysis (DMA) of the cured underfill strips was performed in single cantilever mode under $1 \mathrm{~Hz}$ sinusoidal strain loading. The storage modulus $\mathrm{E}^{\prime}$, loss modulus $\mathrm{E}^{\prime \prime}$, and loss factor were recorded from room temperature to $200{ }^{\circ} \mathrm{C}$ at a heating rate of $3^{\circ} \mathrm{C} / \mathrm{min}$.

\section{RESULTS AND DISCUSSION}

\section{A. Moisture Absorption in Acid Anhydride Curing System}

The moisture absorption in uncured underfill in normal lab environment at $22{ }^{\circ} \mathrm{C} 40-50 \%$ relative humidity was recorded. 


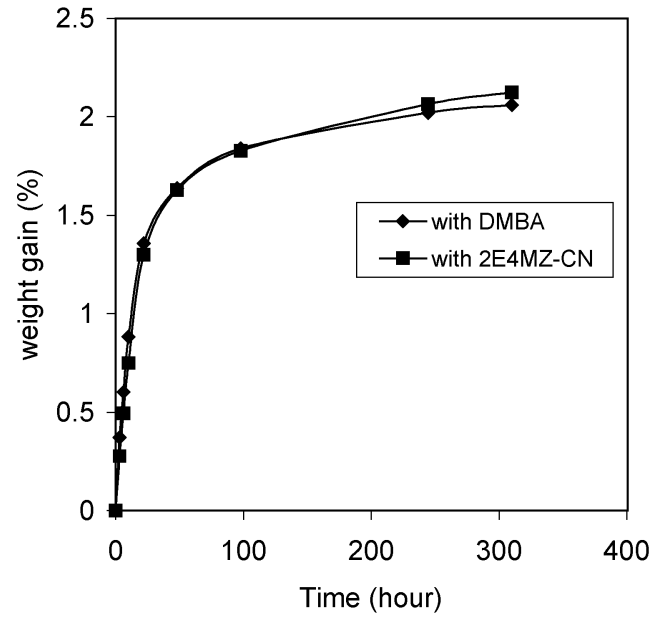

(a)
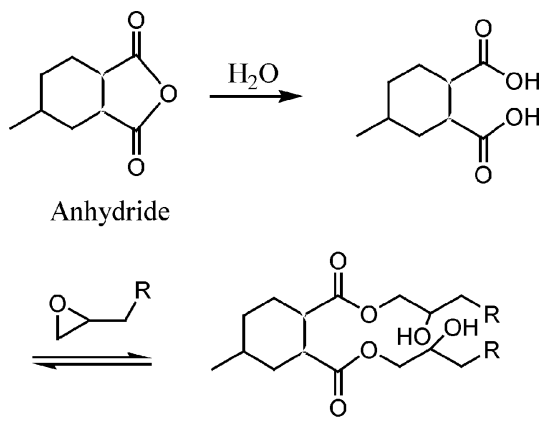

Beta Hydroxy Ester

(b)

Fig. 1. (a) Moisture absorption in EPON8281+MHHPA with different catalyst in ambient lab environment (sample thickness: $2 \mathrm{~mm}$ ). (b) Formation of $\beta$-hydroxy ester.

The underfill absorbed moisture very rapidly at room temperature, and the moisture absorption for an extended time was as high as $2.0 \%$ for EPON8281+MHHPA with a thickness of $2 \mathrm{~mm}$ [Fig. 1(a)], and 3.5\% for ERL4221+MHHPA system with cobalt(II) acetylacetonate as catalyst (Fig. 2). It was also observed that the viscosity increased with the moisture absorption.

\section{B. Effect of Moisture Absorption on Adhesion}

Die shear adhesion samples were prepared with freshly prepared underfill ERL4221+MHHPA+CAA on silicon nitride passivated silicon dies, and then cured after different time of delay in ambient lab environment allowing moisture absorption or in a desiccator without moisture absorption. The die shear adhesion strength after curing was measured (Tables I and II). The moisture absorption in underfill before curing reduced the adhesion strength significantly. Some silane coupling agents were added into the underfill and die shear samples were prepared. Although the addition of coupling agent into underfill can improve the adhesion hydrolytic stability after the curing [8], the addition of coupling agent does not improve the adhesion strength if the underfill absorbed moisture before curing. Die shear adhesion samples were also prepared on $\mathrm{BCB}$ or polyimide passivated dies. It was found that adhesion strength to $\mathrm{BCB}$ and polyimide also decreased after the uncured

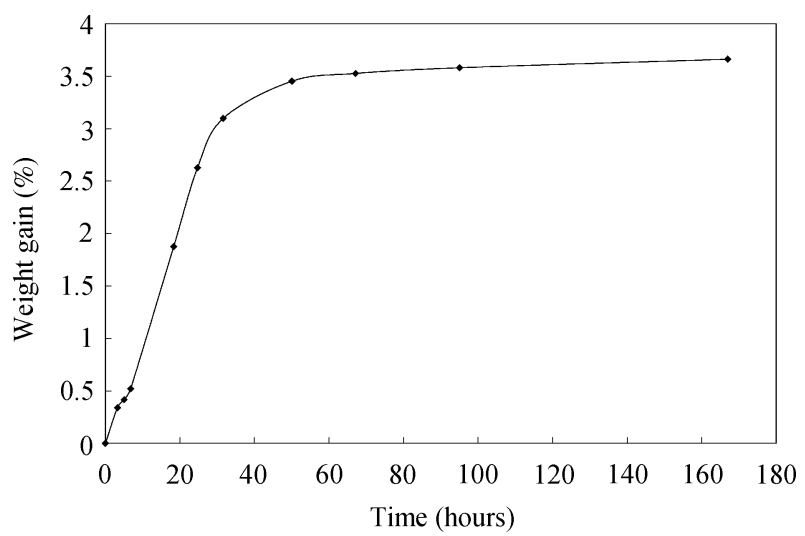

Fig. 2. Moisture absorption in ERL4221+MHHPA with cobalt acetylacetonate as catalyst in ambient lab environment (sample thickness: $2 \mathrm{~mm}$ ).

TABLE I

ADHESION STRENGTH (MPa) OF UNDERFILL ERL4221+MHHPA+CAA CURED at DifFERENT TIME DELAY IN a DesicCATOR AFTER ASSEMBLING (SUBSTRATE: SiN)

\begin{tabular}{lccc}
\hline & Cured immediately & One day & One week \\
\hline No CA & $59.3 \pm 8.1$ & $57.0 \pm 8.4$ & $56.8 \pm 11.3$ \\
With A187 & $56.2 \pm 7.9$ & $56.0 \pm 6.5$ & $51.4 \pm 9.9$ \\
With A1110 & $58.1 \pm 13.5$ & $56.3 \pm 7.6$ & $51.2 \pm 9.0$ \\
\hline
\end{tabular}

The die shear samples were kept in a desiccator before curing.

TABLE II

ADHESION STRENGTH (MPa) OF UNDERFILL ERL4221+MHHPA+CAA CUREd at DifFERENT Time Delay IN AMBIENT LAB ENVIRONMENT AFTER ASSEMBLING (SUBSTRATE: SiN)

\begin{tabular}{lccc}
\hline & Cured immediately & one day & 1 week \\
\hline No CA & $59.3 \pm 8.1$ & $14.0 \pm 4.3$ & $9.1 \pm 4.9$ \\
With A187 & $56.2 \pm 7.9$ & $14.0 \pm 5.6$ & $6.2 \pm 1.7$ \\
With A1110 & $58.1 \pm 13.5$ & $16.1 \pm 7.4$ & $8.1 \pm 3.8$ \\
\hline
\end{tabular}

The die shear samples were left in normal lab condition before curing.

underfill absorbed moisture (Table III), indicating this effect does not depend on the passivation materials, although the adhesion hydrolytic stability after curing strongly depends on the hydrophilicity of passivation materials [8]. This indicated that moisture absorption deteriorated the bulk property of underfill materials.

Die shear samples were also prepared with EPON8281+ MHHPA systems with DMBA and 2E4MZ-CN as catalysts on silicon nitride. Table IV lists the adhesion results for EPON8281+MHHPA+DMBA system. EPON8281+MHHPA+2E4MZ-CN showed similar results. The adhesion strength of EPON8281+MHHPA also decreased if the underfill was allowed to absorb moisture before curing. Water ( $2 \%$ of underfill) was added into underfill, and then die shear samples were assembled and cured immediately. In this case, the adhesion strength after curing was same as the adhesion strength of the underfill without any moisture absorption. These results indicated that it took some time for the moisture to react with the underfill and then cause the lower adhesion of underfill. If the water is absorbed (added) into the underfill just before curing, the unreacted water can diffuse out during curing. This implies that the moisture absorbed right before the curing of underfill during assembly is not expected to affect 
TABLE III

ADHESION STRENGTH (MPa) OF ERL4221+MHHPA+CAA TO BCB AND S200 PI OF DIE SHEAR SAMPLES CURED 48 HOURS AFTER ASSEMBLING

\begin{tabular}{lcc}
\hline & kept in a desiccator & kept in normal lab condition \\
\hline BCB & $40.4 \pm 8.7$ & $17.3 \pm 5.8$ \\
S200 PI & $64.4 \pm 5.8$ & $15.5 \pm 5.6$ \\
\hline
\end{tabular}

TABLE IV

ADHESION STRENGTH OF EPON8281+MHHPA+DMBA TO SiN

Condition

Immediately cured after assembled

Cured 24 hrs after assembling, kept outside a desiccator

Cured 24 hrs after assembling, kept inside a desiccator

Cured 4 days after assembling, kept outside a desiccator

Cured 4 days after assembling, kept inside a desiccator

Cured 7 days after assembling, kept outside a desiccator

With $2 \% \mathrm{H}_{2} \mathrm{O}$ added, cured immediately after assembling

TABLE V

VISCOSITY OF ERL4221+MHHPA+CAA $+2 \% \mathrm{H}_{2} \mathrm{O}$ AT DIFFERENT TIME AFTER MIXING

\begin{tabular}{|c|c|}
\hline Time delay (hours) & Viscosity (Pa-s) \\
\hline 0 & 0.16 \\
\hline 5 & 1 \\
\hline 11 & 2.5 \\
\hline 29 & 11 \\
\hline 55 & 70 \\
\hline
\end{tabular}

the adhesion of the wafer level underfill materials if little time is allowed for the water to react with the underfill before the final curing.

The behavior that the moisture absorption before curing causes the low adhesion of epoxy cured with acid anhydride does not depend on the catalyst, nor depend on the epoxy resin. With the presence of water, epoxy cured with acid anhydride system gives $\beta$-hydroxy ester, which is shown in Fig. 1(b). Beta-hydroxy ester has low adhesion strength.

\section{Influence of Absorbed Moisture on Viscosity}

When the underfill materials were allowed to absorb moisture, it was observed that the viscosity of the underfill materials increased with the absorption of moisture. The viscosity of the underfill was nonhomogenous in the underfill materials. The layer on the top showed higher viscosity than the bottom layer. The moisture diffusion is slower than the reaction of water with the underfill. Thus it is difficult to measure the viscosity of underfill versus the moisture absorption directly. For this reason, $2 \%$ of water was added into the underfill formulation ERL4221+MHHPA+CAA, viscosity of underfill with addition of $2 \%$ water versus time was recorded with a rheometer at room temperature. It showed significant increases with the time. The viscosity of underfill without any added water or absorbed water at ambient environment showed no significant increase (Table V).

\section{Influence of Absorbed Moisture on Curing and Glass Transition Temperature After Curing}

The effect of absorbed moisture on curing of underfill was further investigated with a differential scanning calorimeter. Fig. 3 shows the DSC curing profiles of ERL4221+MHHPA+

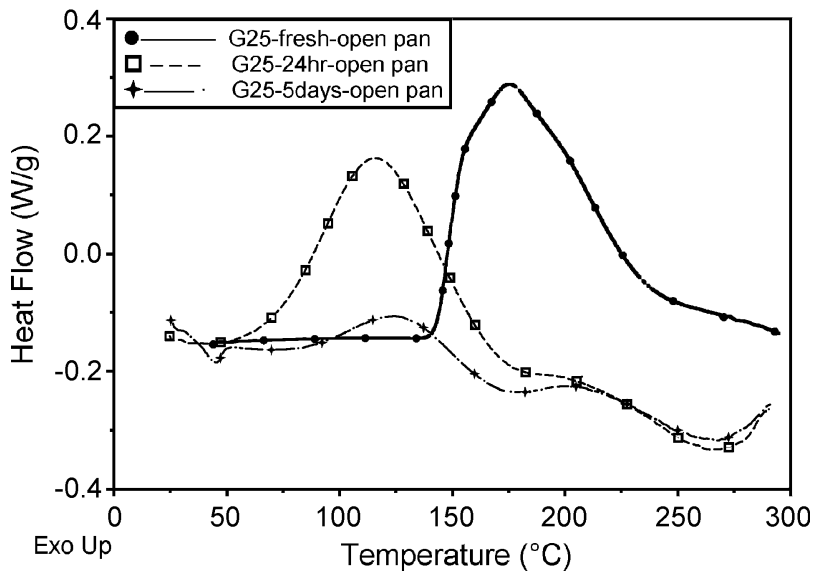

Fig. 3. DSC curing profile of ERL4221+MHHPA+CAA (G25) in an open aluminum pan after the samples aged in the pan under normal lab environment for different time.

TABLE VI

SUMMARY OF DSC ANALYSIS OF ERL4221+MHHPA+CAA IN AN OPEN PAN

\begin{tabular}{ccccc}
\hline $\begin{array}{c}\text { Delay time } \\
\text { (hour) }\end{array}$ & $\begin{array}{c}\text { Onset of } \\
\text { curing }\left({ }^{\circ} \mathrm{C}\right)\end{array}$ & $\begin{array}{c}\text { Peak } \\
\text { temperature }\left({ }^{\circ} \mathrm{C}\right)\end{array}$ & $\begin{array}{c}\text { Heat } \\
(\mathrm{J} / \mathrm{g})\end{array}$ & $\mathrm{T}_{\mathrm{g}}\left({ }^{\circ} \mathrm{C}\right)$ \\
\hline 0 & 143 & 175 & 297 & 190 \\
24 & 70.4 & 117 & 247 & 119 \\
120 & 87 & 125 & 51 & 119 \\
\hline
\end{tabular}

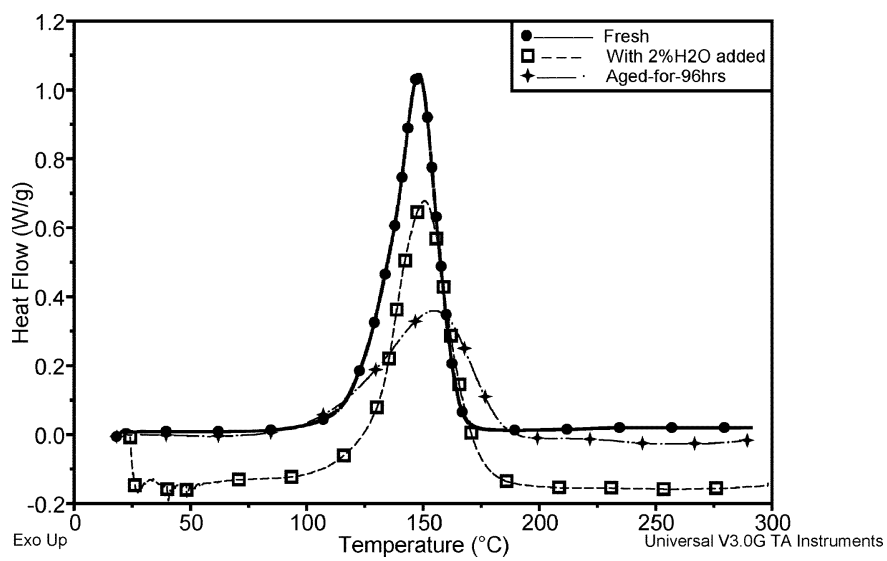

Fig. 4. DSC curing profile of EPON8281+MHHPA+2E4MZ-CN.

CAA after moisture absorption for different time. Table VI summarizes the results. It was found that partial curing took place during moisture absorption at room temperature, which was indicated by the increase of viscosity and decrease of exothermic peak area during DSC scanning (Fig. 3 and Table VI). It was also observed that the curing onset temperature decreased significantly after the moisture absorption for system catalyzed with cobalt(II) acetylacetonate (Fig. 3). It was reported that the complexed water in metal acetylacetonate can catalyze the curing reaction of epoxy and acid anhydride system [9]. The absorbed moisture can catalyze the curing reaction of this system. Also, the glass transition temperature was reduced.

The influence of moisture absorption on curing of EPON8281+MHHPA systems was also studied. Fig. 4 shows the DSC curing profile of EPON8281+MHHPA+2E4MZ-CN after moisture absorption for different time. The curing onset 
TABLE VII

SUMMARY OF DSC ANALYSIS OF HEAT OF EPON8281+MHHPA+DMBA

\begin{tabular}{ccc}
\hline Delay time (hour) & Reaction heat $(\mathrm{J} / \mathrm{g})$ & $\mathrm{Tg}\left({ }^{\circ} \mathrm{C}\right)$ \\
\hline 0 & 290 & 122 \\
24 & 260 & 105 \\
96 & 183 & 100 \\
with $2 \% \mathrm{H}_{2} \mathrm{O}$ added & 290 & 107 \\
\hline
\end{tabular}

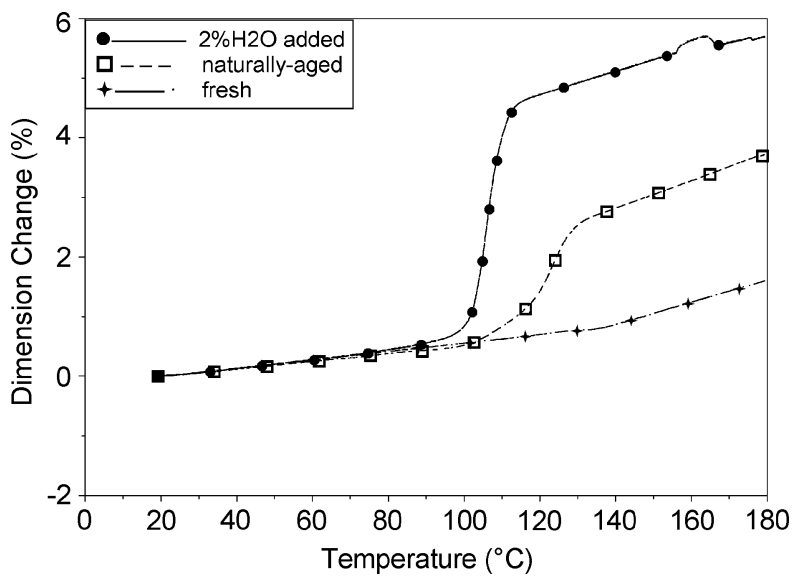

Fig. 5. TMA profile of EPON8281+MHHPA+2E4MZ-CN cured after different conditioning.

temperature was not significantly reduced by the absorption of moisture from the environment. However, the exothermic peak area was less than the peak area of the fresh sample. This indicated that partial curing took place during the moisture absorption at room temperature. DSC curing profile was also recorded for system with $2 \%$ of water added. The curing profile was the same as the curing profile of fresh sample. It was also observed that the glass transition temperature of the cured underfills decreased after the moisture absorption before curing. Similar behavior was observed for EPON8281+MHHPA+DMBA system. The DSC analysis results for EPON8281+MHHPA+DMBA are summarized in Table VII.

\section{E. Influence of Absorbed Moisture on Thermo-Mechanical Properties of Underfill Materials}

The effect of absorbed moisture on thermomechanical properties of underfill was also studied. Three specimens were cured for one formulation: fresh underfill with no absorbed water, with $2 \%$ added $\mathrm{H}_{2} \mathrm{O}$, and naturally absorbed water during long time of staying in normal lab environment. A thermal mechanical analyzer (TMA) and a dynamic mechanical analyzer (DMA) were used to characterize the thermomechanical properties of cured underfill. Fig. 5 shows TMA profile of EPON8281+MHHPA+2E4MZ-CN cured after different conditioning. Fig. 6 shows the DMA profiles of EPON8281+MHHPA+2E4MZ-CN cured after different conditioning. Due to the relatively high thickness of underfill, the added water cannot evaporate from the underfill during curing, contrary to the DSC experiment with a very small amount of sample in an open pan. Moisture absorbed or added in underfill can cause decrease of the glass transition temperature. It was

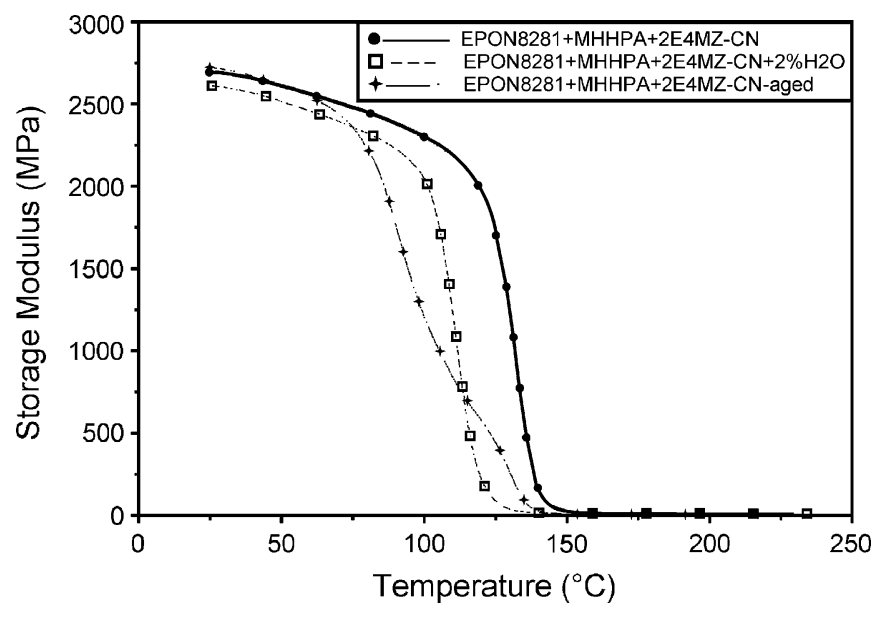

Fig. 6. DMA profile of cured EPON8281+MHHPA+2E4MZ-CN.

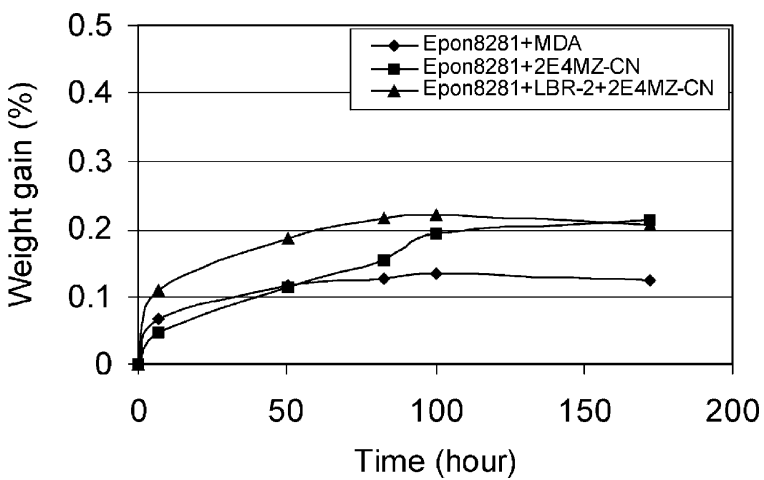

Fig. 7. Moisture absorption of underfill under normal lab environment (sample thickness: $2 \mathrm{~mm}$ ).

interesting to find that temperature range for glass transition of the sample cured from naturally moisture-absorbed underfill became much wider. This is because that moisture absorption is not homogenous. The top layer absorbed more moisture than the bottom layer of underfill materials. After curing of the material, the top layer has low glass transition temperature than the bottom layer, and thus the whole materials shows broader glass transition range. However, the modulus of these samples at room temperature did not change much.

\section{F. Moisture Absorption in Non-Acid Anhydride Cured System}

Model underfill formulations were prepared with non-acid anhydride as curing agent. The moisture absorption under ambient lab environment was recorded. Fig. 7 shows the results. The moisture absorption is around $0.2 \%$ for EPON8281+LBR2+2E4MZ-CN and EPON8281+2E4MZ-CN systems. It is even lower for EPON8281+MDA system. The moisture absorption for non acid anhydride cured system is much lower than that of acid anhydride cured system.

Adhesion samples were also assembled with those underfill formulations, placed in different environment for $48 \mathrm{~h}$, and then cured. Table VIII shows the adhesion strength. Obviously, there is no significant difference in the adhesion strength between the die shear samples with and without moisture absorption. The low moisture absorption in non-acid anhydride cured system has no significant effect on the adhesion of underfill after curing. 
TABLE VIII

AdHesion Strength (MPa) of Die SHEar SAMPLE CuREd AFTER SOME TIME Delay (SUBSTRATE: SiN)

\begin{tabular}{lcc}
\hline & kept in a desiccator for 48 hours & kept outside a desiccator \\
\hline EPON8281+MDA & $43.1 \pm 14.2$ & $45.0 \pm 12.3$ \\
EPON8281+LBR-2+2E4MZ-CN & $52.8 \pm 7.3$ & $55.3 \pm 3.8$ \\
EPON8281+2E4MZ-CN & $40.2 \pm 9.6$ & $39.0 \pm 14.1$ \\
\hline
\end{tabular}

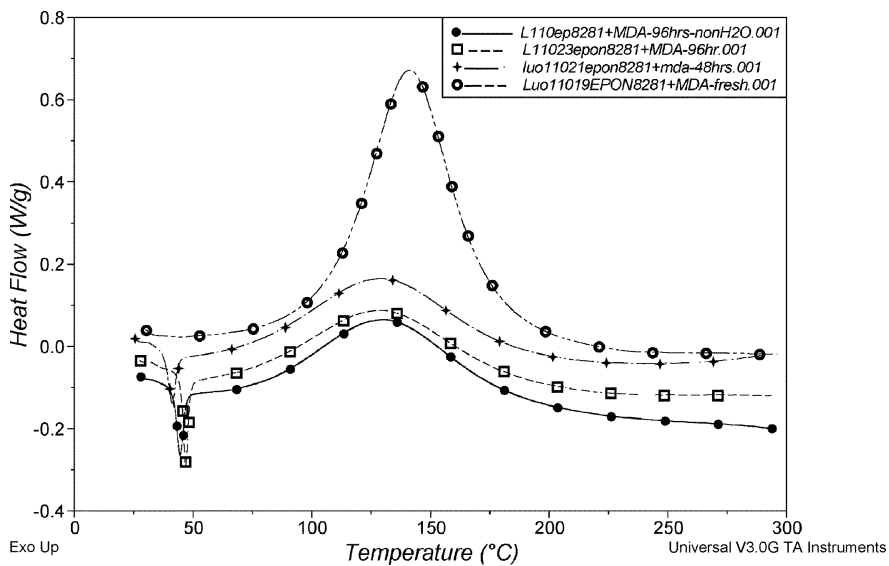

Fig. 8. DSC curing profiles of EPON8281+MDA systems.

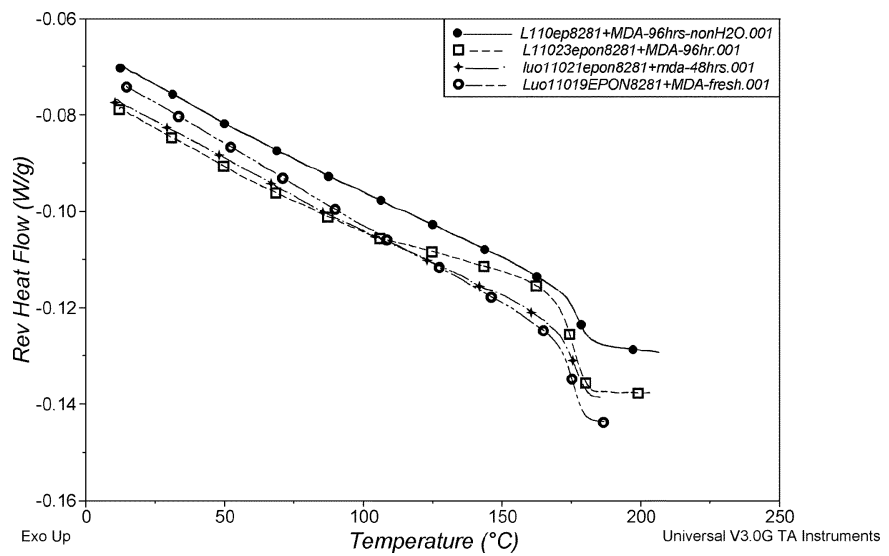

Fig. 9. DSC reversible heat profiles of EPON8281+MDA system at different condition after curing.

DSC experiments were also performed for non-acid anhydride cured system to investigate if the absorbed moisture affects the curing of the underfill systems and the glass transition temperature of the cured samples. Fig. 8 shows the curing profiles of EPON8281+MDA system. MDA can cure the epoxy at room temperature. Thus, the heat of reaction detected by DSC decreased with the increase of age of the underfill at room temperature. It was also noticed that there is a small endothermic peak around $45{ }^{\circ} \mathrm{C}$ after the underfill was left at ambient temperature for several days. This could be due to the melting of MDA crystal. The crystal in the mixture was obviously not perfect, thus showed a significantly lower melting temperature. There is no significant difference between samples aged for $96 \mathrm{~h}$ at room temperature with and without moisture absorption. This indicated that the low moisture absorption has no effect on the curing of EPON8281+MDA system. Fig. 9 shows the reversible heat flow of the cured sample in the DSC pan. The results showed that there is no difference in glass transition temperature among these three samples.

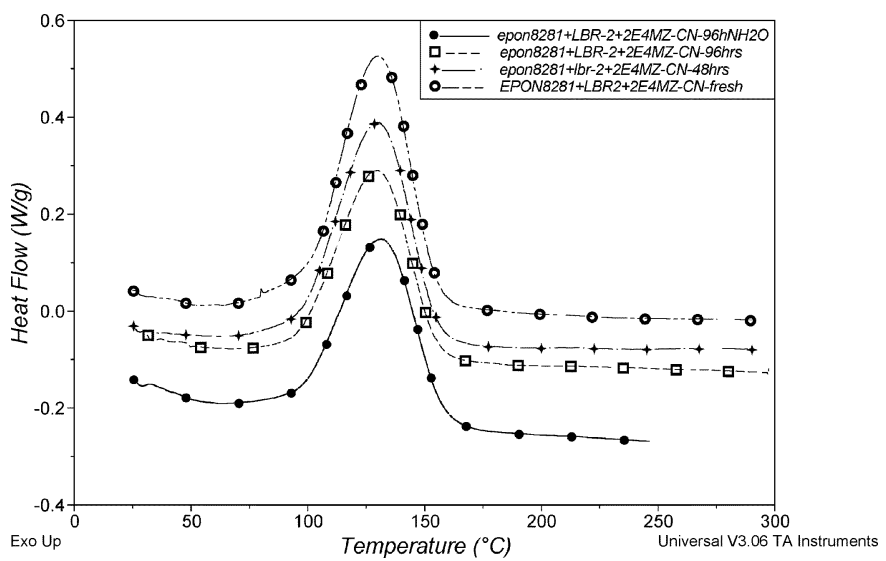

Fig. 10. DSC curing profile for EPON8281+LBR+2E4MZ-CN system.

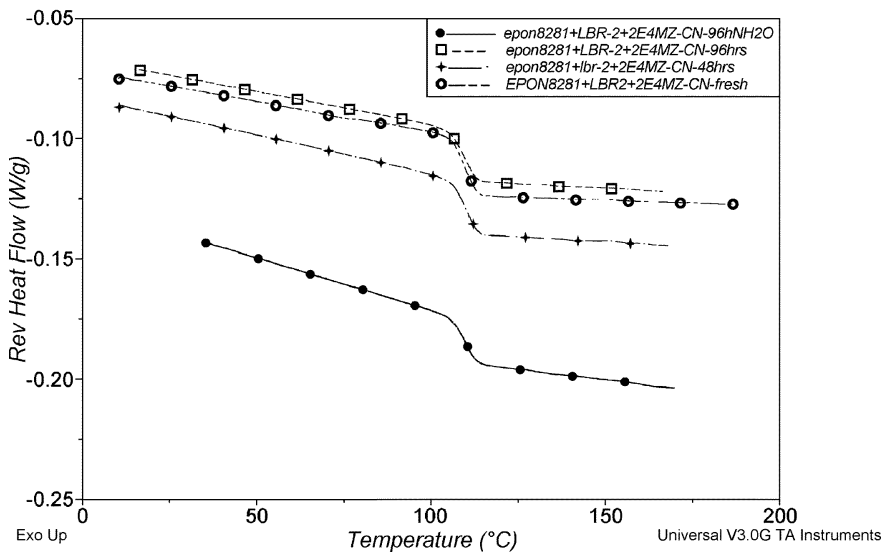

Fig. 11. DSC reversible heat flow after the curing for EPON8281+LBR+2E4MZ-CN system.

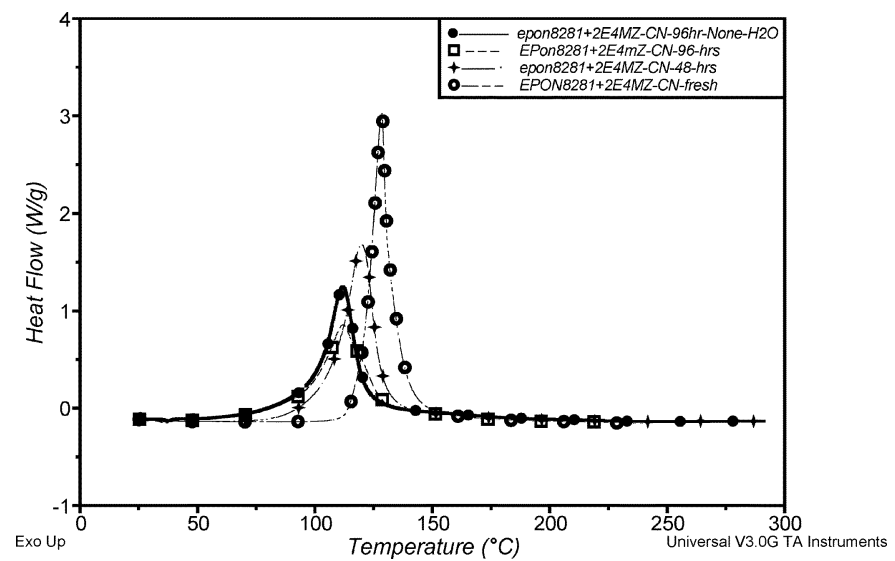

Fig. 12. DSC curing profile of EPON8281+2E4MZ-CN.

Fig. 10 shows the DSC curing profiles for EPON8281+LBR+ 2E4MZ-CN system and Fig. 11 shows the reversible heat flow after the curing. Obviously, the system cured slowly at room temperature, but not as much as MDA cured system. Also, the absorbed moisture has no influence on the curing of the system, or on the glass transition temperature after curing.

Fig. 12 shows the DSC curing profile of EPON8281+ 2E4MZ-CN system. Curing can take place slowly at room temperature, and curing peak temperature moves to lower 


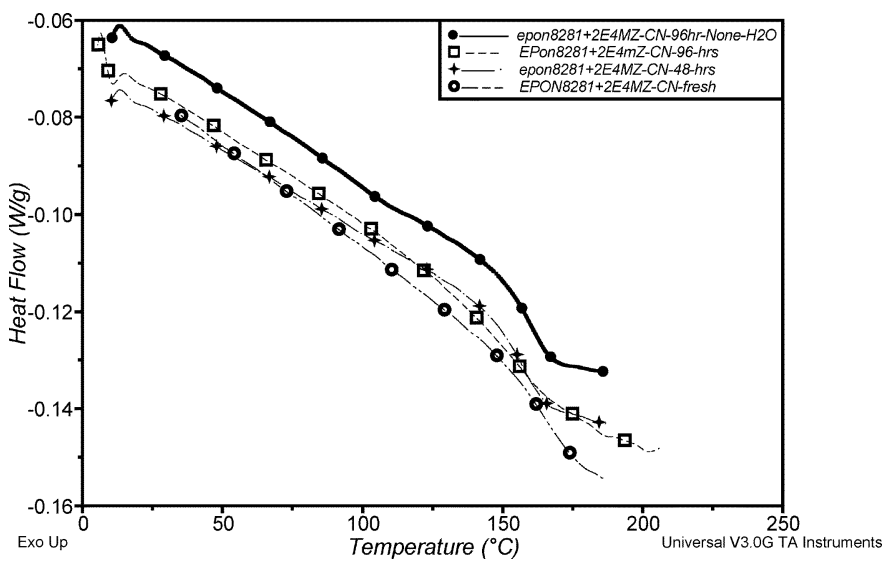

Fig. 13. DSC reversible heat flow after curing for EPON8281+2E4MZ-CN system.

temperature after the aging at room temperature. Comparing the samples after $96 \mathrm{~h}$ of aging at room temperature with and without moisture absorption, we can find out that the moisture absorption has no effect on the curing. The curing reaction is not catalyzed by the presence of moisture. Fig. 13 shows the glass transition temperature after curing. The glass transition temperature was not affected by the absorbed moisture.

\section{CONCLUSION}

Epoxy underfill material can absorb moisture before curing. For epoxy cured with non-acid anhydride, the moisture absorption is low, and the absorbed moisture has no significant effect on the properties of cured underfill materials. For epoxy cured with acid anhydride, the moisture absorption before curing can be more than $2.0 \%$, and the absorbed moisture can affect the properties significantly. The absorbed moisture can catalyze the curing reaction between acid anhydride and epoxy with the presence of cobalt acetylacetonate as catalyst. The glass transition temperature of the cured samples is reduced after the underfill absorbs the moisture before curing. The adhesion strength decreases dramatically after the underfill absorbs the moisture before curing. Also, it takes time for the absorbed moisture to react with the system and show the effect.

\section{REFERENCES}

[1] C. P. Wong, S. Luo, and Z. Zhang, "Flip the chip," Science, vol. 290, p. 2269, Dec. 22, 2000

[2] D. Suryanarayana, T. Y. Wu, and J. A. Varcoe, "Encapsulants used in flip-chip packages," in Proc. 43rd Electronic Components and Technology Conf., Orlando, FL, 1993, p. 193.

[3] C. P. Wong, S. H. Shi, and G. Jefferson, "High performance no-flow underfills for low cost flip-chip applications: materials characterization," IEEE Trans. Comp., Packag., Manufact. Technol. A, vol. 21, p. 360, June 1998.

[4] A. Babiarz and S. J. Adamson, "Underfill and encapsulation," IEEE Trans. Adv. Packag., vol. 23, p. 51, May 2000.

[5] Q. Tong, B. Ma, E. Zhang, A. Savoca, L. Nguyen, C. Quentin, S. Luo, H. Li, L. Fan, and C. P. Wong, "Recent advances on a wafer-level flip chip packaging process," in Proc. 50th Electronic Components \& Technology Conf., Las Vegas, NV, May 2000, p. 101.
[6] K. S. Chian, S. H. Lim, S. Yi, and W. T. Chen, "Effect of moisture on the curing behavior of underfill," in Proc. Int. Symp. Electronic Materials and Packaging, Hong Kong, Nov. 30-Dec. 2 2000, p. 289.

7] C. P. Wong and R. McBride, "Pre-encapsulation cleaning methods and control for microelectronics packaging," IEEE Trans. Comp., Packag., Manufact. Technol. A, vol. 17, pp. 542-552, Dec. 1994.

[8] S. Luo and C. P. Wong, "Influence of temperature and humidity on adhesion of underfill for flip chip packaging," in Proc. 51st Electronic Components \& Technology Conf., Lake Burena Vista, FL, May 2001, p. 155.

[9] S. H. Shi and C. P. Wong, "Effect of the complexed moisture in metal acetylacetonate on the properties of the nonflow underfill materials," $J$. Appl. Polym. Sci., vol. 73, pp. 103-111, 1999.

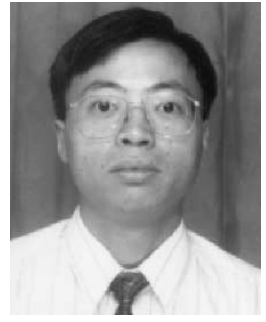

Shijian Luo (M'00) received the B.S. and M.S.E. degrees in polymer materials from Shanghai Jiao Tong University, Shanghai, China, in 1989 and 1992 , respectively, and the M.S. and Ph.D. degrees in polymers from the Georgia Institute of Technology, Atlanta, in 1998 and 2002, respectively.

He has published over ten journal papers and over 20 conference papers in the area of electronic packaging. He currently works for Micron Technology, Inc., Boise, ID. His expertise is in materials and processes for electronic packaging.

Dr. Luo received several "Best Paper of Session" awards from conferences. $\mathrm{He}$ is a member of the IEEE CPMT Society.

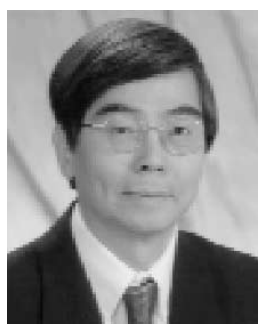

C. P. Wong (SM'87-F'92) received the B.S. degree in chemistry from Purdue University, West Lafayette, $\mathrm{IN}$, and the Ph.D. degree in organic/inorganic chemistry from Pennsylvania State University, University Park.

After his doctoral study, he was awarded two years as a Postdoctoral Scholar at Stanford University, Stanford, CA. He spent 19 years at AT\&T Bell Laboratories. He is a Regents Professor with the School of Materials Science and Engineering and a Research Director at the NSF-funded Packaging Research Center, Georgia Institute of Technology, Atlanta. He holds over 40 U.S. patents, numerous international patents, has published over 400 technical papers and 300 key-notes and presentations in the related area. His research interests lie in the fields of polymeric materials, high Tc ceramics, materials reaction mechanism, IC encapsulation, in particular, hermetic equivalent plastic packaging, electronic manufacturing packaging processes, interfacial adhesions, PWB, SMT assembly, and components reliability.

Dr. Wong received the AT\&T Bell Laboratories Distinguished Technical Staff Award in 1987, the AT\&T Bell Labs Fellow Award in 1992, the IEEE Components, Packaging and Manufacturing Technology (CPMT) Society Outstanding and Best Paper Awards in 1990, 1991, 1994, 1996, and 1998, the IEEE Technical Activities Board Distinguished Award in 1994, the 1995 IEEE CPMT Society's Outstanding Sustained Technical Contribution Award, the 1999 Georgia Tech's Outstanding Faculty Research Program Development Award, the 1999 NSFPackaging Research Center Faculty of the Year Award, the Georgia Tech Sigma Xi Faculty Best Research Paper Award, the University Press (London, UK) Award of Excellence, the IEEE Third Millennium Medal in 2000, the IEEE EAB Education Award in 2001 and was elected a member of the National Academy of Engineering in 2000. He is a Fellow of AIC and AT\&T Bell Labs. He served as the Technical Vice President (1990 and 1991), the President (1992 and 1993) of the IEEE-CPMT Society, the IEEE TAB Management Committee (1993-1994), the Chair of the IEEE TAB Design and Manufacturing Committee (1994-1996), the IEEE Nomination and Appointment Committee (1998-1999), and the IEEE Fellow Committee (2001 to the present). 